\title{
A Survey on the Status of Hospital-Based Early Intensive Intervention for Autism Spectrum Disorder in South Korea
}

\author{
Ju Young Lee', Duk-Soo Moon', Suk-Ho Shin², \\ Hee-Jung Yoo ${ }^{3}$, Hee-Jung Byun ${ }^{1}$, and Dong-Soo Suh ${ }^{1}$ \\ 1 Department of Psychiatry, Seoul Metropolitan Children's Hospital, Seoul, Korea \\ ${ }^{2}$ Dr. Shin's Child and Adolescent Psychiatric Clinic, Seoul, Korea \\ ${ }^{3}$ Department of Psychiatry, Seoul National University Bundang Hospital, Seongnam, Korea
}

\author{
국내 자폐스펙트럼장애 아동의 병원 기반 조기 집중 중재 실태 조사

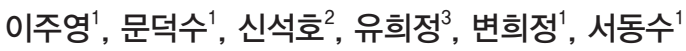 \\ 서울특별시 어린이병원 정신건강의학과, ${ }^{1}$ 신석호 소아청소년 정신과, ${ }^{2}$ 서울대학교 분당서울대학교병원 정신건강의학과 ${ }^{3}$
}

\begin{abstract}
Objectives: Early intensive interventions are very important for children with autism spectrum disorder. We examined the actual conditions of hospital-based early intensive interventions for autism spectrum disorder in Seoul, in order to help develop and implement an evidence-based early intensive intervention model for use in Korea.

Methods: Nine hospital-based institutes running an early intensive intervention program for children with autism spectrum disorder responded to a questionnaire in September 2014. They provided a brief introduction to their program, explained its theoretical bases, and reported the number of children, their age, intervention time, duration and so on.

Results: In the majority of the institutions, the intervention was provided for over 20 hours every week, and the theoretical bases included various applied behavioral analysis (ABA) methods and other therapies (language and occupational therapy). The therapist-child ratio ranged from 1:1 to 5:3. Various types of therapists were involved, including behavioral analysts, special education teachers and (or) language pathologists. There was only one clinic where the behavioral analyst was the main therapist. Usually, the intervention was terminated just before the child entered elementary school. The main merit of the hospital-based intervention in our survey was the effectiveness of the multi-disciplinary intervention plan and its other merits were the accuracy of the diagnosis, its ability to be combined with medicine, and so on. Conclusion: The current hospital-based early intensive intervention programs provide interventions for over 20 hours per week and employ multidisciplinary approaches. However, there are very few institutes for children with autism and very few intervention specialists and specialist education courses in the country. We need more educational programs for intervention therapists and have to try to develop policies which encourage the implementation of an evidence-based early intensive intervention program nationwide.
\end{abstract}

Key Words: Autism spectrum disorder; Early intensive intervention; Applied behavioral analysis (ABA), Hospital-based intervention.

Received: December 19, 2016 / Revision: March 28, 2017 / Accepted: April 18, 2017

Address for correspondence: Dong-Soo Suh, Department of Psychiatry, Seoul Metropolitan Children's Hospital, 260 Heolleung-ro, Seocho-gu, Seoul 06801, Korea

Tel: +82-2-570-8001, Fax: +82-2-570-8324, E-mail: 88jesus@seoul.go.kr

서 론

자폐스펙트럼장애는, 2013년에 Diagnostic and Statistical Manual of Mental Disorders, fourth edition text revision (DSM-IV-TR)에서 Diagnostic and Statistical Manual of Mental disorders, fifth edition(DSM-5)으로 정신과 진단 체계

This is an Open Access article distributed under the terms of the Creative Commons Attribution Non-Commercial License (http://creativecommons.org/licenses/by-nc/4.0) which permits unrestricted non-commercial use, distribution, and reproduction in any medium, provided the original work is properly cited.
의 대대적 변환이 있으면서 진단 기준이 바뀌었다. 3세 이전이 라는 명확한 나이 기준이 발달 초기에 발생이라는 좀 더 모호 한 나이 기준으로 바뀌긴 하였으나, 어려서부터 시작되어 대부 분의 환자가 일생에 걸쳐 오랫동안 그 증상이 지속되는 발달 상의 질환임은 여전하며,2) 사회적 상호 의사소통의 어려움과 제한적이고 반복적인 관심 및 행동이상을 보인다는 점은 공통 으로 하고 있다.

자폐스펙트럼장애를 포함한 발달관련 장애는 완치를 위한 치료 방법이 아직 없으나, 연구가 거듭될수록 보다 더 좋은 예 
후를 위한 조기 발견과 진단, 조기 치료의 중요성이 강조되고 있다. 나이가 들어서 치료 중재를 하는 것보다 조기에 중재를 할수록 그 효과가 좋고 오래 지속된다는 보고들이 많다. ${ }^{3-6)}$ 따라서 자폐스펙트럼장애는 조기에 발견하여 진단하고 조기 에 집중적인 치료적 중재를 하는 것이 현재까지는 치료 표준 으로 제시되고 있다.

한국에서는 2007년 대한소아청소년 정신의학회에서 전반적 발달장애의 한국형치료 권고안을 발표하였다. 이에 따르면, 보 다 조기에 진단 및 체계적이고 구조화된 특수교육과 행동 치료 를 받을 것을 권유하고 있으며, 조기의 집중적인 행동치료적 접근은 지속적인 경과 향상과 긍정적인 예후와 관계가 있다.7.8)

미국 소아청소년 정신의학회에서 2014년에 발표한 치료 권고 안에서도 대체로 비슷한 기준을 제시하고 있다. ${ }^{2}$ 치료 제안으 로 가족이 적절히 받을 수 있는, 근거 중심의 구조화된 교육적 행동적 개입을 받을 것을 권유하고 있다. 근거 중심의 치료로 서 행동 치료적 접근, 의사소통에 필요한 치료적 접근, 교육적 치료 접근 등을 제시하고 있다. 행동 치료적 접근은 응용행동 분석(applied behavioral analysis, $\mathrm{ABA}$ )을 기본으로 한 조기 집중 행동 중재(early intensive behavioral intervention)를 개 별적, 집중적으로 시행할 것을 권고하고 있으며, 나아가 일상 생활과 학습, 상호 의사소통, 사회 기술, 직업 기술에까지 확장 하여 적용된다고 이야기하고 있다. 의사소통 치료 접근은 언어 재활사가 함께 개입하여 언어적 의사소통이 되지 않을 경우 대체 의사소통 수단을 이용하여 의사소통을 촉진할 수 있도 록 권고한다. 교육적 치료 접근은 행동치료적 접근처럼 매우 구조화된, 개별 수준에 적합한 집중적인 개입을 가족을 포함 한 팀으로 시행하도록 권고한다. 본 연구에서 언급하는 조기 집중 중재는 미국 소아청소년 정신의학회의 치료 권고안에서 언급된 치료의 개념을 차용하였다.

우리나라 전체적으로 자폐스펙트럼장애와 관련하여 근거 기반 치료를 제공할 수 있는 기관에 대한 욕구는 크며, 점차적 으로 증가하고 있으나 실제로 이용 가능한 제반 시설은 매우 부족하다. 자폐스펙트럼장애인의 경우에는 국가에서 제공하 는 재활치료 바우처 서비스의 이용률이 낮은데, 그 이유가 적 절한 치료 기관이 없기 때문이라는 의견은 이러한 현실을 반영 한다. ${ }^{9}$ 국가에서 제공하는 재활치료 서비스가 늘어나면서 그 이용률 또한 증가하고 있지만, 여전히 적절한 치료를 제공하 는 기관이 부족하다고 이용자들은 느끼고 있다.9 현재까지 자 폐스펙트럼장애 아동을 대상으로 한 조기 집중 중재를 하는 기관에 대한 조사는 제대로 되어 있지 않으며, 몇몇 치료기관 도 서울을 포함한 수도권에 집중되어 있는 실정이다.

또한 자폐스펙트럼장애에서의 조기 집중 중재에 대한 분명 한 정의나 구성 요소에 대한 가이드도 우리나라 실정에 맞게
확립되어 있지 않아 기관의 자체적인 보고만 이루어지고 있으 며, 다학제적 접근이 이루어지는 기관이 있기는 하나 이마저도 운영 방식에 대한 자료가 없는 상태이다. 이러한 상황에서 치료 자들 역시 근거기반적인 치료 접근을 하려고 해도, 다학제적으 로 접근할 수 있는 환경을 만들고 운영하기가 현실적으로 쉽 지 않다.

이에 본 연구는 근거중심의 조기 집중 중재 모델을 개발하 고 보급하는데 그 기초가 되는 선행작업을 위해, 치료 기관이 집중되어 있는 서울 지역에서 병원 기반 조기 집중 중재 프로그 램을 운영하고 있는 기관의 치료 구성 및 실태를 조사하였다.

\section{방 법}

병원 기반 치료 조기 집중 중재 프로그램을 운영하고 있는 서 울 소재 9개 기관을 대상으로 2014년 9월, 약 한 달 동안 설문 조사를 진행하였다. 설문 대상인 9 개 기관 모두에서 설문 조 사에 응하였다. 9 개 기관 중에 공공 병원 3곳, 대학병원 1곳, 의원이 5 곳이었다. 문항은 총 21 개로 19 개는 객관식 복수 응 답 가능 문항, 2 개는 주관식 문항이었으며, 복수 응답 시에는 그중 가장 중요하게 생각하는 요인을 추가적으로 조사하여 우선 순위를 확인하고자 하였다. 응답은 기관 운영자나 조기 집중 중재에 관여하는 프로그램 책임자에게 전자 메일로 설문 지를 보내서 자가보고식으로 답을 작성하도록 하였다. 운영하 는 프로그램의 간단한 소개 요청과 함께 설문 내용은 통상적 으로 권고되는 조기 집중 중재의 형식에 맞추어 구성하였으 며, 조기 집중 중재의 정의와 개념에 대한 인식, 프로그램의 구성, 참여 아동의 연령, 교육이나 치료의 시간, 인원과 규모, 치료 인력 구성 등에 대한 내용을 포함하였다. 치료 관련해서 는 진단과 평가 과정, 치료 종결 결정 기준과 종결 후 연계 상 황에 대한 내용이 포함되었고, 프로그램 구성과 운영에 이용 하는 이론적 배경을 함께 조사하였다.

\section{결 과}

\section{조기 집중 중재의 성격(Table 1)}

조기 집중 중재의 성격에 대해서는 세 가지 설문 문항을 통 해 알아보았다. 첫 번째는 조기 집중 중재를 정의하는 요인에 대한 것이었는데, 이론적 배경을 선택한 곳이 7곳으로 가장 많 았으며, 뒤를 이어 아동의 연령이 6곳, 운영시간이 5 곳, 주당 중재 시간이 3 곳, 한 반의 아동 수가 1 곳이었다. 이론적 배경 은 조기 집중 중재를 정의하는 요인의 우선 순위에서도 가장 많은 응답을 받았다(3곳). 기타 자유 의견으로 특정시간 이상 치료자와 구성원들이 안정된 관계 형성과 지속적 상호작용, 전 
Table 1. Characteristics of early intensive intervention (multiple choice)

\begin{tabular}{|c|c|c|}
\hline \multicolumn{3}{|c|}{ Factors for defining early intensive intervention (multiple choice) } \\
\hline Factor & No. & The most importance (no. of clinics) \\
\hline Total intervention time & 5 & 0 \\
\hline Weekly number of intervention time & 3 & 1 \\
\hline Theoretical base of intervention & 7 & 3 \\
\hline Age of children & 6 & 1 \\
\hline Number of children of a class & 1 & 0 \\
\hline \multicolumn{3}{|c|}{ Child's diagnosis (multiple choice) } \\
\hline Diagnosis & \multicolumn{2}{|r|}{ No. } \\
\hline Autism spectrum disorder & \multicolumn{2}{|r|}{$9(100 \%)$} \\
\hline Intellectual disability & \multicolumn{2}{|r|}{4} \\
\hline ADHD or emotional problems & \multicolumn{2}{|r|}{1} \\
\hline \multicolumn{3}{|c|}{ Main theoretical base of intervention (multiple choice) } \\
\hline Theory & No. & The most importance (no. of clinics) \\
\hline Discrete trial training (DTT) & 7 & 3 \\
\hline Pivotal response treatment (PRT) & 3 & 0 \\
\hline Verbal behavior therapy (VR) & 5 & 1 \\
\hline Floor time & 1 & 0 \\
\hline Treatment and education of autistic and related communication (TEACCH) & 4 & 0 \\
\hline $\begin{array}{l}\text { Total inclusion of various therapies [language, cognition \& learning, } \\
\text { occupational therapy (sensory integration), play, etc.] }\end{array}$ & 6 & 3 \\
\hline Picture exchange communication system (PECS) & 6 & 0 \\
\hline
\end{tabular}

문치료가 병합되는 것이 우선 중요하다고 응답한 기관이 1 곳 있었다. 두 번째는 조기 집중 중재 참여 아동의 진단(장애) 유 형이었는데, 9 개 기관 모두 자폐스펙트럼장애 아동이 참여하고 있었고, 이 외에 지적 장애 아동도 참여하는 곳이 4곳, 주의력 장애 및 정서장애도 조기 집중 중재 참여의 대상이 되는 곳 은 1곳이었다. 세 번째는 조기 집중 중재 프로그램 운영에 있 어 치료의 주요 이론적 배경에 대해 알아보았다. 이에 대해서 는 모든 기관에서 복수 응답을 하여, 한 가지 이론만으로 접 근하는 경우는 없었다. 응용행동분석(ABA) 기반의 비연속수 행(discrete trial training, DTT)이 7곳으로 가장 많았으나 이 에 못지 않게 언어/인지/작업(감각통합)/놀이 등 각 치료를 시간표에 통합하여 제공하는 경우나 그림교환의사소통체계 (picture exchange communication system, DECS)로 중재접 근을 하는 곳도 6 곳으로 많았다. 이론 반영의 우선 순위를 보 았을 때, 비연속수행과 통합치료는 3곳으로 공동 1 위에 올랐다.

그룹별 치료 아동 수와 그룹별 참여하는 치료사 수(Table 2)

그룹을 구성한 아동 수는 2 명에서 8 명까지 다양하였다. 그룹 별로 5명으로 구성된 기관이 3곳으로 가장 많았고, 그 다음 이 4 명으로 2 곳이었다. 그룹별로 참여하는 치료사 수는 1 명에 서 6 명까지 다양하였다. 이를 바탕으로 한 그룹별 아동과 치 료사의 비율을 계산하였을 때 아동 대 치료사 비율이 5:3에서 1:1 미만까지 나타났다. 그중 아동과 치료사의 비율이 1:1로 운
영되는 곳이 4곳으로 가장 많았다.

치료사의 구성(복수응답)(Table 2)

그룹 치료에 주로 참여하는 교사의 구성은 매우 다양하였 는데, 그중에서 언어치료사, 감각통합(작업)치료사, 인지 치료 사가 5 곳으로 가장 많았으며, 행동치료사가 4곳으로 그 뒤를 이었다. 조기 집중 중재 시 필요한 치료사의 우선 순위에서는 행동치료사, 인지치료사, 감각통합치료사가 필요하다고 응답 한 기관이 각각 1 곳이었다.

\section{조기 집중 중재 프로그램의 주당 운영 횟수와 회당 운영 시간}

(Table 2)

조기 집중 중재 프로그램의 주당 운영 횟수는 최소 2 회, 최 대 6 회로 주 1 회인 곳은 없었다. 회당 운영시간은 2 시간과 6 시 간이 각각 3 곳으로 가장 많았고, 나머지는 2.5 시간, 3 시간, 5 시간인 곳이 각각 1 곳이었다. 이를 바탕으로 기관별 주당 총 운영 시간을 계산해 보았을 때, 4시간, 6 시간, 7.5 시간, 12 시간, 15 시간, 24 시간(2곳), 25 시간, 30 시간으로 다양한 시간으로 운 영하고 있었고, 주 20시간 이상은 4곳으로 50\%를 차지하였다.

치료의 시작 시점과 종결 시점(복수응답)(Table 3)

조기 집중 중재 프로그램의 치료 시작 시점은 대체적으로 만 2세나 3세 때 모집하는 기관이 각각 6곳, 7곳으로 가장 많았다. 
Table 2. Intervention forms and therapist specialties

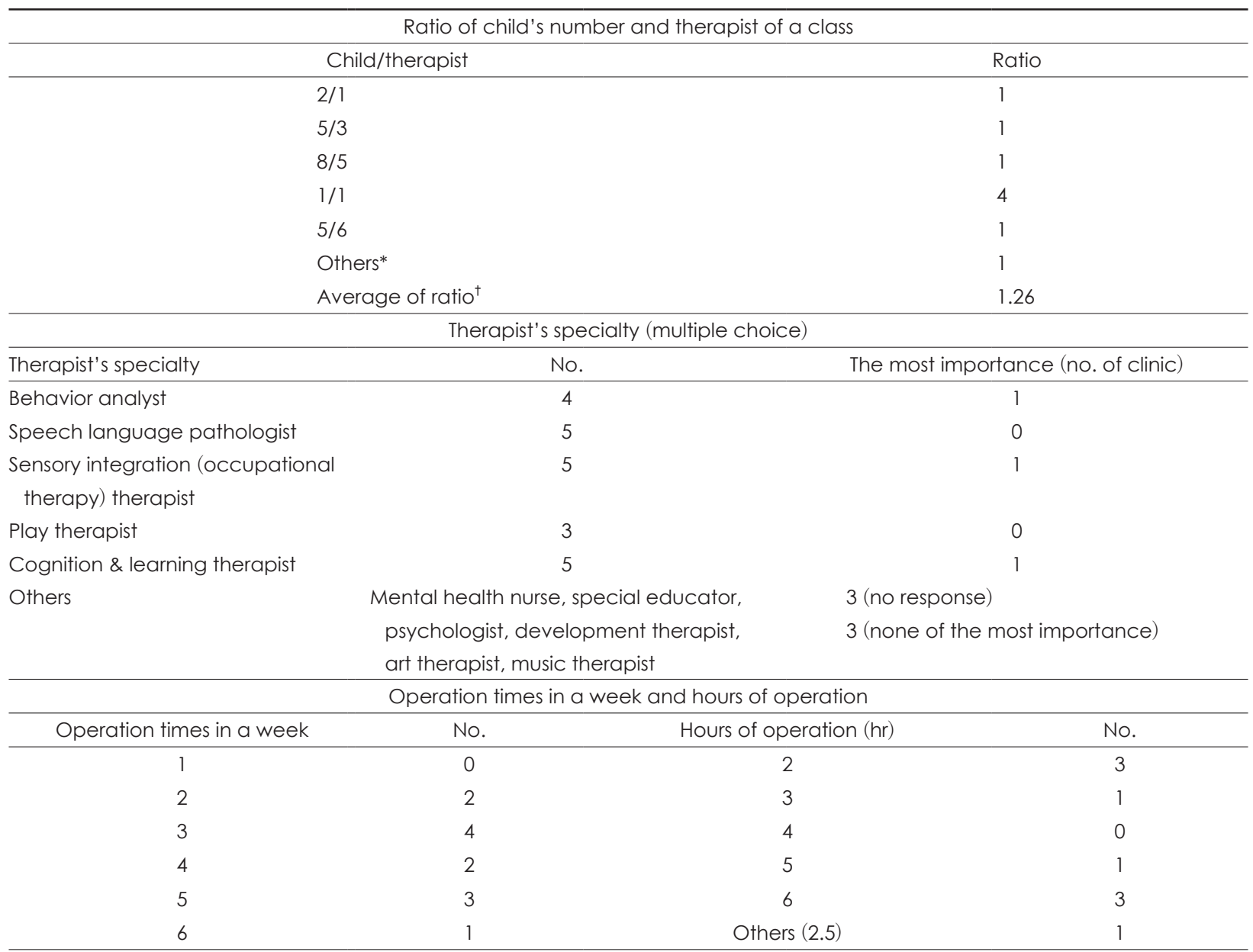

*less than $1,{ }^{\dagger}$ the 'other' is excluded in the average calculation

Table 3. Starting age and finishing age of intervention (multiple choice)

\begin{tabular}{cccc}
\hline $\begin{array}{c}\text { Starting age } \\
\text { (months) }\end{array}$ & No. & $\begin{array}{c}\text { Finishing age } \\
\text { (months) }\end{array}$ & No. \\
\hline $12-24$ & 0 & $24-36$ & 0 \\
$24-36$ & 6 & $36-48$ & 1 \\
$36-48$ & 7 & $48-60$ & 4 \\
$48-60$ & 3 & $60-72$ & 5 \\
$60-$ & 0 & $72-$ & 3 \\
\hline
\end{tabular}

종결 시점은 그보다 약 2년 긴 만 4세와 5 세가 각각 4곳, 5 곳 으로 가장 많은 시점으로 조사되었다. 설문 문항에 있지는 않 았으나, 각 치료기관별로 프로그램의 시작과 종결 시점을 바탕 으로 계산된 치료 기간은 2년인 곳이 3곳으로 가장 많았고, 3 년인 곳이 2곳이었다. 즉, 설문 대상 기관들에서 조기 집중 중 재가 이루어지는 기간이 만 2세에서 만 5세의 영유아기에 집 중되고 있음을 알 수 있다.
Table 4. Recommended therapy after the intervention (multiple choice)

\begin{tabular}{lc}
\hline \multicolumn{1}{c}{ Therapy } & No. \\
\hline Language therapy & 6 \\
Sensory integration therapy & 2 \\
Play therapy & 1 \\
Cognitive therapy & 5 \\
Group therapy for social function enhancement & 6 \\
AAC, PECS & 1 \\
Outpatient clinic follow up & 5 \\
Others (another ABA) & 1 \\
\hline AAC:
\end{tabular}

AAC: augmentative and alternative communication, $A B A$ : applied behavioral analysis, PECS: picture exchange communication system

치료 종결 후 주로 연계하는 치료 프로그램(복수응답)(Table 4)

치료 종결 이후에는 언어 치료와 사회성 향상을 위한 그룹 치료가 각각 6 곳으로 가장 많았다. 그 다음으로는 인지치료와 공교육 적응을 우선시하며 외래 추적 관찰하는 경우가 각각 5 곳으로 뒤를 이었다. 
Table 5. Advantage of hospital-based intervention (multiple choice)

\begin{tabular}{|c|c|}
\hline \multicolumn{2}{|c|}{ Advantage of hospital-based intervention (multiple choice) } \\
\hline Advantage & No. \\
\hline Accurate diagnosis & 7 \\
\hline Accompany with medicine & 7 \\
\hline Multi-disciplinary intervention plan & 8 \\
\hline Care-giver education & 5 \\
\hline Evidence based intervention & 4 \\
\hline Decreased economic burden with NHI inclusion & 6 \\
\hline \multicolumn{2}{|l|}{$\mathrm{NHI}$ included or not } \\
\hline Type & No. \\
\hline Almost NHI included & 3 \\
\hline Part of NHI included & 5 \\
\hline Almost NHI not included & 2 \\
\hline
\end{tabular}

NHI: national Health Insurance

\section{건강보험 포함 여부를 포함한 병원 기반 치료의 장점(Table 5)}

9개의 기관 중에서 조기 집중 중재에 낮병원 형태의 건강보 험이 적용되는 기관이 3곳이었고, 의사 면담 및 약물 치료 등 건강 보험 관련 치료비가 일부 포함된 기관이 5 곳이었으며, 모 두 비급여로 운영하는 기관이 2곳이었다. 병원 기반 치료의 장 점은 통합적 치료 계획을 수립할 수 있다는 응답이 8곳으로 가 장 많았고, 두 번째로는 진단을 정확하게 한다는 것과 약물 치 료를 병행할 수 있다는 점을 7곳에서 장점으로 꼽았다.

\section{고 찰}

'조기 집중 중재’라는 용어에서 제시하는 것처럼 조기 집중 중재는 세 가지 요소, 즉 1) 치료의 시작 시점, 2) 치료의 강도, 3) 사용되는 중재방법이 성격을 결정하는 데 중요하다. 먼저, 조사 결과의 치료 시작 시점은 만 2세에서 3세로, 통상적인 치 료 권고안의 내용에 부합하였다. 조사에서 만 3세가 가장 많 고, 만 2세가 그 다음으로 많았는데, 보통 자폐스펙트럼장애 의 징후를 발견하는 아이의 나이가 2세 이전이 약 $64 \%$ 정도 로 과반수 이상이며, 3세 이전에는 $80 \%$ 가 넘는 높은 발견율 을 보이고, 이후 바로 병원을 찾는 비율 또한 가장 높다는 국 내 연구의 결과와 일치한다. ${ }^{10)}$ 또한 만 2세부터 장애진단이 가 능한 것도 치료 시작 시점에 영향을 미칠 수 있는데, 장애 진 단을 받으면 치료비용의 일부를 도움 받아서 부담을 줄일 수 있어, 이러한 점이 조기 집중 중재의 시작 시기에 고려될 수 있 는 부분이다.

두 번째로, 치료의 강도는 여러 치료 권고안에서 권유되고 있 는 치료 시간을 반영하여 '총 치료 시간이 강도를 반영하는 지표에 포함된다고 생각된다. 본 연구에서 조사된 주당 총 치 료 시간을 계산한 결과를 보면, $50 \%$ 이상의 기관에서 20 시간
이상의 치료 시간을 유지하고 있었는데, 주당 최소 20 시간 이 상1)의 시간을 권유하고 있는 미국의 조기 집중 중재와도 부 합되고 있다.

세 번째로, 사용되는 중재방법은 통상적인 치료 권고안2,7,12) 에서 제시된 것과 같이 특수 교육과 행동 치료적 접근을 하고 있었다. 다만, 운영을 하는 이론적 배경이 다양하고, 치료 프 로그램도 한 가지가 아닌 다양한 치료와 다학제적 접근 방식 을 취하고 있었다. 이는 그만큼 자폐스펙트럼장애의 특성상 다양한 치료와 중재가 요구되기 때문인 것으로 생각된다.

조기 집중 중재를 마친 이후에도 대부분의 기관에서 다양한 치료 및 교육을 받도록 연계를 하고 있었는데, 이는 자폐스펙 트럼장애의 특성, 아동의 기능 및 적응 수준, 기관의 사정 등에 따라 달라지는 것으로 보인다. 특히 언어치료와 사회성 증진 치료가 많이 연계되는 이유는 자폐스펙트럼장애 아동의 경우 언어 발달이 잘 안 되는 경우가 많고, 사회성은 평생에 걸쳐 지 속되는 어려움인데다가 나이가 들수록 사회적 관계에의 요구 가 많아지기 때문이라고 생각된다. 인지치료(특수교육) 연계가 많은 것은 자폐스펙트럼장애 아동의 약 $56 \%$ 에서 지적 장애가 공존함 ${ }^{13)}$ 을 고려할 때, 조기 집중 중재 이후에도 여전히 인지 발달의 어려움이 많고 발달의 불균형이 지속적으로 나타나기 때문일 것으로 생각된다. 공교육에 대한 일차 적응을 우선시 하며 외래 추적 관찰을 하는 경우는 대부분의 자폐스펙트럼장 애 아동들이 조기 중재 후에 유치원 또는 어린이집에서 통합교 육(공교육형태)을 받고, 이후에 초등학교로의 전이가 이루어지 게 되기 때문이다. 조기 중재 치료 후에 조기 집중 중재를 받 은 직후 또는 1 2년 후 초등학교 입학할 시기가 오는데, 한국 의 현실상 대부분의 아동들은 통합교육을 공교육의 형태로 받기 때문에 이때부터 성인이 될 때까지 학교에서 발달장애 아 동들을 통합 또는 특수 교육으로 흡수하여 가르치기 때문인 것으로 생각된다. 다른 행동치료기관으로의 연계에 답을 한 기관도 있었는데, 기관의 사정으로는 1년 밖에 조기 치료를 받 지 못했기 때문에 추가적으로 집중치료를 받기 위해 연계한 것 으로 생각된다.

국내 발달장애 치료의 현실과 치료의 효과를 감안하면, 병원 기반 치료는 실제 장점을 많이 가지고 있다. 일단, 병원에서 정 확한 진단이 이루어지고 있으며, 근거 중심의 치료를 적용하 고 실행하기에 가장 용이하고, 필요한 경우 적극적으로 약물 치료를 함께 하고, 치료사들과 임상의사가 지속적인 협력을 이어갈 수 있다. 따라서 임상의사는 다양한 관점의 접근이 치 료적으로 잘 이루어지기 위해서 다양한 치료 영역과 의사소 통을 할 수 있는 역량이 요구되기도 한다.

치료사 구성 결과를 보면, 최근의 치료 방침에서는 집중적 행동치료를 가장 중요하게 권하고 있지만 행동치료사를 우선 
적으로 두는 경우는 한 치료기관 밖에 없었으며, 나머지 치료 기관은 모두 그 우선순위가 다른 것으로 나타났다. 이번 조사 에서 한 종류의 치료사로만 구성된 기관의 경우 치료사가 모두 특수교사였는데, 이는 특수교사가 행동치료적 접근 등 여러 특수교육 방법을 이용한 치료를 하는 경우가 많기 때문이라 고 생각된다. 우리나라의 경우 현재 행동치료사에 관한 국가 자격증 제도가 없으며, 이로 인해 행동치료사라 하더라도 일 부는 미국의 행동치료사 자격증을 취득한 경우이거나, 현재 그 치료사 자격증을 취득하기 위한 과정을 밟으면서 행동치료사 를 하고 있는 경우가 대부분이다. 따라서, 이번 조사 결과는 현재 우리나라에서 행동치료사가 조기 집중 치료에 있어서 치 료사로서 우선 순위가 될 수 없는 실정을 그대로 반영하고 있 으며, 앞으로 행동치료사 등 전문 인력 양성을 위한 교육 과정 마련과 양질의 치료사를 배출하기 위한 자격 제도가 보완되어 야 할 것으로 생각된다.

국민건강보험 적용 여부와 병원 연계 치료의 장점 요인 조사 와 관련해서는, 건강 보험 적용으로 인해 보호자 부담이 감소 되는 것이 장점이라고 응답한 기관이 많은 점은 흥미롭다. 이 번 조사에서 더 자세한 운영 방식에 대해서 조사하지는 않았 으나, 특히 낮병원을 운영하는 경우 건강보험 적용을 할 수 있 어서, 비급여 치료비를 어느 정도 탄력적으로 적용하여 보호자 의 자기 부담금이 줄어드는 쪽으로 적용이 가능하기 때문인 것으로 생각된다. 캐나다에서 조사된 한 연구에 따르면, 자폐 스펙트럼장애의 경우 첫 해 정신과 방문이 연 7 14회이며, 5년 후에 방문횟수는 2 4회로 줄지만 약물 복용 비율이 증가한 다고 한다. ${ }^{14)}$ 미국에서 자폐스펙트럼장애 아동 가족의 경우 아 동의 건강을 위해 지출하는 비용이 사보험을 든 가계가 공공 보험을 든 가계보다 약 5 배가 높다고 하여, 치료 비용의 지출 측면에서 공공보험이 사보험보다 강점을 가짐을 알 수 있었 다. ${ }^{15)}$ 이런 다른 나라의 자료를 보아도, 자폐스펙트럼장애 아동 의 치료에서 공공보험의 역할이 중요시 됨을 알 수 있다.

전국민 건강 보험 제도를 운영하고 있는 우리나라에서 조사 된 연구 ${ }^{16)}$ 에 의하면 자폐스펙트럼장애 아동의 치료 비용이 약 물은 월 평균 6 만 3천 원, 교육-행동 요법은 놀이 치료나 언어 치료 등 여러 치료가 모두 월 평균 20만 원 내외였다. 약물의 경우 보험 적용이 되므로 가계의 비용 부담이 적은데, 나머지 다른 치료들은 보험이 되지 않아서 비용이 높게 나왔다. 교육행동 치료의 경우 평균 3가지 이상을 받고 있는 것으로 조사 되어, 한 달에 3 가지를 받는다고 가정할 때 월 60만 원의 비용 이 수년간 드는 것을 추정할 수 있다. 보건복지부에서 2015년 발표한 자료 ${ }^{17)}$ 에 의하면, 장애 아동의 경우 경제적 사정에 따라 월 14 만 원에서 22 만 원 정도의 치료비 지원을 하고 있는데, 가 장 높은 금액인 22만 원을 지원 받는다 하더라도, 월 60만 원
의 치료비에는 턱없이 부족하며, 이마저도 행동치료의 경우는 바우처 기관이 없어 더욱 비현실적인 지원임을 알 수 있다.

만약 부족한 점을 보완하여 건강 보험 제도의 개선이 이루 어진다면, 더욱 병원 연계 치료의 장점을 살리면서, 발달장애 아동에 대한 체계적인 치료 지원을 강화할 수 있다. 앞으로 우리나라의 자폐스펙트럼장애, 나아가 발달장애 아동의 치료 와 관련된 건강 보험 정책의 개선(예를 들면 현재 비급여로 지 불되고 있는 행동치료, 언어치료 등의 건강보험 급여화 혹은 바우처 적용 기간의 충분한 확보나 비용 보조의 현실화 등)이 매우 중요하고 현실에 맞게 보완할 필요성이 있다. 우리나라에 서는 국민 건강보험 외에 건강 관련 민간 보험 유지를 위해 가 계에서 지출을 하고 있는데, 이러한 부분까지도 건강 보험에서 흡수되는 방법을 고려한다면, 치료를 위한 가계의 부담 총액 이 줄어들 수도 있다.

본 연구는 몇 가지 제한점을 가지고 있다. 첫째, 국내 전체 치 료 기관의 실태파악에는 큰 한계가 있는데, 의료 기관과 연계 된 치료기관만 조사가 이루어졌으며, 치료기관이 가장 많이 분포하고 있기는 하지만 서울이라는 한정된 지역을 대상으로 조사하였다는 점이다. 둘째, 치료를 위한 대기 및 모집 상황에 대한 조사는 이루어지지 않아, 거시적으로 병원 연계 조기 집 중 중재에 대해 어느 정도의 치료적 요구가 있는지는 알 수가 없었다. 셋째, 병원 연계 조기 집중 치료를 받는 아동들은 전 체 자폐스펙트럼장애 아동들 중 병원에 올 만큼 심하거나 장 애 진단을 받은 아동일 가능성이 더 많다. 따라서, 그렇지 않 은 자폐스펙트럼장애 아동의 치료 실태를 반영하고 있지는 않 으며, 이에 대한 추가적인 연구가 필요하다. 마지막으로, 기관 의 자가 보고이기 때문에 중재접근 방법, 치료 구성, 병원 연계 치료 기관이 가지는 장점 등과 관련해서는 객관성이 떨어질 수 있으며, 자료의 정확도에 있어서 자가 보고의 한계를 벗어 날 수는 없다.

이 연구의 여러 한계점에도 불구하고 생각할 수 있는 의미는 다음과 같다. 먼저, 국내 병원 연계 조기 집중 중재 기관에 대 한 조사는 이번이 처음이다. 앞으로 더 폭넓은 지역을 대상으 로 조사를 해야 할 필요가 있으며, 병원 연계를 하지 않은 조 기 집중 중재 기관에 대한 실태 조사도 필요하겠다. 두 번째 는 자폐스펙트럼장애를 포함한 발달장애인에 대한 정책을 결 정하는데 참고가 될 수 있다. 2015년 복지부에서 연구한 발달 장애인 재활의료 지원 체계 구축에 관한 연구에서는 발달장 애인을 위한 조기 중재 등 치료 제공 기관이 매우 부족함을 지 적하였는데 ${ }^{16)}$ 이를 활성화할 수 있는 정책의 방향과 방침을 잡아가는데 도움이 될 것으로 생각된다. 세 번째는 임상 의사 들이 자폐스펙트럼장애의 치료에 있어서 근거중심치료를 마 련하며 실행하는데 있어서 앞서 운영하고 있는 치료 기관의 운 
영 실태를 참고하여 더욱 타당한 프로그램을 마련하고 운영 하는데 도움이 될 것으로 생각된다.

\section{결 론}

본 연구를 통해 국내 자폐스펙트럼장애 아동들을 위한 조 기 집중 중재 기관에서 이루어지고 있는 조기 집중 중재의 특 성을 알 수 있었다. 현재 병원 기반 조기 집중 중재 프로그램은 대체적으로 근거 중심 치료에 입각하여 다학제적 접근과 주 20 시간 이상의 치료 집중도를 가지고 있었다. 치료의 중재 방 법과 치료사 구성에 대한 조사를 통해 간접적으로 집중적 치 료에 대한 전문 인력의 부족과 국내 양성 시스템의 부재를 알 수 있었으며, 이에 대한 고민과 해결 마련이 필요한 것으로 생 각된다. 앞으로 근거 중심의 치료 환경이 더 마련되고 이러한 치료 환경이 전국적으로 확대되어 나갈 수 있도록 정책의 마 련과 노력이 필요하다.

중심 단어: 자폐스펙트럼장애; 조기 집중 중재; 응용행동분석; 병원 기반 중재.

\section{Conflicts of Interest}

The authors have no financial conflicts of interest.

\section{REFERENCES}

1) American Psychiatric Association. Diagnostic and Statistical Manual of Mental Disorders (DSM-5). 5th ed. Washington DC: American Psychiatric Association;2013.

2) Volkmar F, Siegel M, Woodbury-Smith M, King B, McCracken J, State M; American Academy of Child and Adolescent Psychiatry (AACAP) Committee on Quality Issues (CQI). Practice parameter for the assessment and treatment of children and adolescents with autism spectrum disorder. J Am Acad Child Adolesc Psychiatry 2014; 53:237-257.

3) McEachin JJ, Smith T, Lovaas OI. Long-term outcome for children with autism who received early intensive behavioral treatment. Am J Ment Retard 1993;97:359-372; discussion 373-391.

4) Sallows GO, Graupner TD. Intensive behavioral treatment for children with autism: four-year outcome and predictors. Am J Ment Re- $\operatorname{tard} 2005 ; 110: 417-438$

5) Tonge BJ, Bull K, Brereton A, Wilson R. A review of evidence-based early intervention for behavioural problems in children with autism spectrum disorder: the core components of effective programs, childfocused interventions and comprehensive treatment models. Curr Opin Psychiatry 2014;27:158-165.

6) Zwaigenbaum L, Bauman ML, Choueiri R, Kasari C, Carter A, Granpeesheh D, et al. Early intervention for children with autism spectrum disorder under 3 years of age: recommendations for practice and research. Pediatrics 2015;136 Suppl 1:S60-S81.

7) Koo YJ, Cho HJ, Yoo HJ, Yoo HI, Son JW, Chung Us, et al. The Korean practice parameter for the treatment of pervasive developmental disorders: non-pharmacological treatment. J Korean Acad Child Adolesc Psychiatry 2007;18:117-122.

8) Hong KE. Korean textbook of child psychiatry. Seoul: Hakjisa;2014. p. $145-162$

9) Kim SH, Lee YH, Hwang JH, Oh MA, Lee MK, Lee NH, et al. 2014 survey on disabled. Sejong: Korean Institute for Health and Social affairs; 2014.

10) Yoon HS. Early recognition of children with autistic spectrum disorder by parents. J Korean Assoc Pers Autism 2006;16:1-15.

11) Maglione MA, Gans D, Das L, Timbie J, Kasari C; Technical Expert Panel; HRSA Autism Intervention Research-Behavioral (AIR-B) Network. Nonmedical interventions for children with ASD: recommended guidelines and further research needs. Pediatrics 2012;130 Suppl 2:S169-S178.

12) Yang MB, Shin SH. Autism spectrum disorder A to Z. Seoul: Sigmapress;2011.

13) Developmental Disabilities Monitoring Network Surveillance Year 2010 Principal Investigators; Centers for Disease Control and Prevention (CDC). Prevalence of autism spectrum disorder among children aged 8 years - autism and developmental disabilities monitoring network, 11 sites, United States, 2010. MMWR Surveill Summ 2014;63:1-21.

14) Perreault S, Croteau C, Mottron L, Tarride J, Dorais M. Psychiatric healthcare utilization and related costs in newly diagnosed Individuals with autism spectrum disorder (Asd) in Quebec (Canada). Value Health 2015;18:A746-A747.

15) Parish SL, Thomas KC, Williams CS, Crossman MK. Autism and families' financial burden: the association with health insurance coverage. Am J Intellect Dev Disabil 2015;120:166-175.

16) KM Kim, IC Choi, SB Lee, KK Lee, KC Paik, JY Lee, et al. Use of various treatment modalities for autism spectrum disorder and mental retardation. J Korean Acad Child Adolesc Psychiatry 2014; 25:73-81.

17) Ministry of Health and Welfare, Korea Disabled people's Development Institute. Research of developmental disabled people's rehabilitation and medical support system construction;2015. 